\title{
Simulation hedge investment portfolios through options portfolio
}

\author{
Miguel Jiménez-Gómez ${ }^{1}$, Natalia Acevedo-Prins ${ }^{2}$, Miguel David Rojas-López ${ }^{3}$ \\ ${ }^{1,2}$ Facultad de Ciencias Económicas y Administrativas, Instituto Tecnológico Metropolitano - ITM, Colombia \\ ${ }^{1,3}$ Facultad de Minas, Universidad Nacional de Colombia, Colombia
}

\begin{abstract}
Article Info
Article history:

Received Jan 7, 2019

Revised Apr 17, 2019

Accepted May 11, 2019

Keywords:

Financial options

Geometrical brownian motion

Hedge

ABSTRACT

This paper presents two hedging strategies with financial options to mitigate the market risk associated with the future purchase of investment portfolios that exhibit the same behavior as Colombia's COLCAP stock index. The first strategy consists in the purchase of a Call plain vanilla option and the second strategy in the purchase of a Call option and the sale of a Call option. The second strategy corresponds to a portfolio of options called Bull Call Spread. To determine the benefits of hedging and the best strategy, the Geometric Brownian Motion and Monte Carlo simulation is used. The results show that the two hedging strategies manage to mitigate market risk and the best strategy is the first one despite the fact that the Bull Call Spread strategy is lower cost.
\end{abstract}

Simulation

Copyright $(0) 2019$ Institute of Advanced Engineering and Science. All rights reserved.

\section{Corresponding Author:}

Miguel Jiménez-Gómez,

Facultad de Ciencias Económicas y Administrativas,

Instituto Tecnológico Metropolitano - ITM,

Medellín, Antioquia, Colombia.

Email: luisjimenez@itm.edu.co

\section{INTRODUCTION}

From the classic financial theory of Modigliani and Miller, hedges do not increase the value of the company because the capital markets are perfect. However, the existence of imperfections in markets such as financial difficulties where there are bankruptcy costs, generate that the hedges increase the value of the Company [1-3]. These preserves of financial difficulties encourage risk management to try to reduce the probability of default to obtain better financing with lower interest rates and greater debt capacity. This leads to greater benefits of tax shields and, in turn, lower financing costs [4]. For this reason, there is evidence in the scientific literature of the benefits of hedges such as the investigations of Joseph [5], Judge [6], Tai [7], and Domínguez and Tesar [8] and Jiménez, Acevedo and Castaño [9].

One of the key functions of risk management is to measure a possible loss. Using measured risk, a financial institution may have sufficient capital reserves to save a potential loss and then maintain normal financial activities when a market undergoes a downward movement in the near future [10].

Market risk is one of the main risks faced by financial institutions. Market risk refers to the uncertainty of profits at a future date that is caused by movements of financial market variables [11]. Other authors affirm that the risk is the possibility of losses generated by changes in the factors that affect the value of an asset $[12,13]$. There is a wide range of financial instruments to mitigate market risk from the simplest strategy to the most complicated strategy [14]. Upward risk in an investment portfolio is a manifestation of market risk. The upward risk is the risk that the price in the future rises above the target expected by the investor and the purchase of financial instruments is made at a price more expensive than expected. This risk is measured from the perspective of the loss for investor buyers caused by adverse changes in market prices. 
Financial derivatives are widely used by the financial management of companies. Among financial derivatives, the financial options that can be used for hedging and investment stand out. With the current high volatilities in the financial markets and the high degree of uncertainty in the general economic environment, financial options are adequate to mitigate market risk. With financial options, a large number of hedging strategies are created for any situation in the market [14].

The objective of this paper is to demonstrate the benefits of hedge with financial options on Colombia's COLCAP stock index for future investment portfolio buyers that replicate the index. This is done through two hedging strategies, the first with the traditional strategy of buying Call options and the second with a portfolio of options called Bull Call Spread. Geometrical Brownian Motion with the COLCAP price index and Monte Carlo simulation the best hedging strategy is determined modeled.

\section{RESEARCH METHOD}

An option is a contract that gives the option owner the right to buy or sell an underlying asset at a specific exercise price on or before a specific date. The seller of that option has the obligation to carry out the transaction when the owner chooses the option [15]. An option that gives the owner the right to buy at a specific price that is known as a purchase option; conversely, an option that gives the owner the right to sell at a specific price is known as a put option. The purchase of an option is known as a long position (or short position). Normally, a purchase option is exercised when the exercise price remains below the value of the active active market, while the purchase option is exercised when the price of the aesthetic exercise is applied to the market value [16]. When the expiration date of the option is synonymous with the exercise of the option, the buyer will lose to the seller the premium paid for the option. Therefore, the price of an option and, therefore, the price of an option, is the key to options trading strategies [15].

This paper determines through Monte Carlo simulation the best hedging strategy to mitigate market risk using two hedging strategies. The first strategy uses the call option purchase on the COLCAP stock index and the second strategy uses a portfolio of options called Bull Call Spread where a call option is purchased and a call option is sold with a strike price higher than the previous option. The Bull Call Spread strategy is shown in the Figure 1 where the red line represents the net result of combining the financial options.

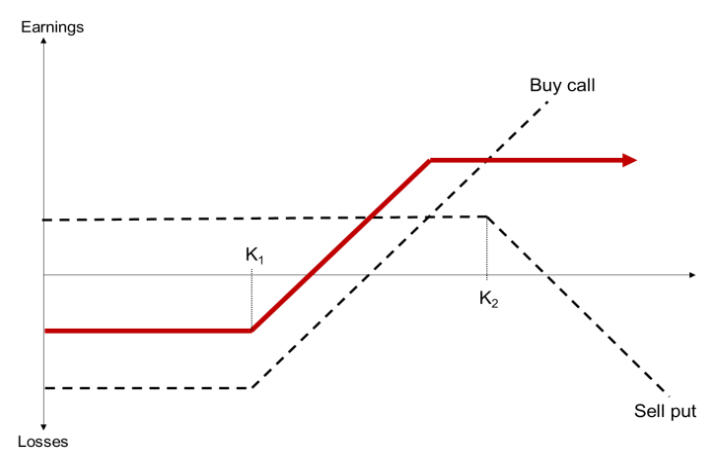

Figure 1. Hedging strategy bull call spread

The first strategy is a plain vanilla strategy where the buyer is hedged by the increase in the price of the asset. So the strategy is to pay the premium of the option Call ATM (At The Money), in other words, the option provides a positive compensation to the buyer in the scenario where the price of the COLCAP index is above the strike price $\mathrm{K}_{1}$ and that, in turn, this strike price is equal to the last known price of the COLCAP. The (1) shows the price hedged with the first strategy.

$$
\text { Hedged Price option Call }=-\left(-\mathrm{S}_{\mathrm{T}}+\max \left(\mathrm{S}_{\mathrm{T}}-\mathrm{K}_{1}, 0\right)-\text { Call option premium }\right)
$$

The second hedge strategy is not part of the plain vanilla strategies because it is done with a portfolio of options. In that strategy, the buyer pays the premium for an ATM Call option, this option is the same as the first strategy, and receives the premium for selling an ITM Call option (In The Money) with a strike price $\mathrm{K}_{2}$ that is higher than the current price COLCAP at \$ 50. The (2) shows the price hedged this portfolio of options called Bull Call Spread. 
Bull Call Spread $=-\left(\begin{array}{c}-\mathrm{S}_{\mathrm{T}}+\max \left(\mathrm{S}_{\mathrm{T}}-\mathrm{K}_{1}, 0\right)-\max \left(\mathrm{S}_{\mathrm{T}}-\mathrm{K}_{2}, 0\right) \\ -\operatorname{premium}_{\text {Call }}+\operatorname{premium~Call~}_{2}\end{array}\right)$

The two hedging strategies are proposed from the point of view of the investor who will be a future investment portfolio that replicates the COLCAP stock index. This is a low-cost form of hedge because instead of covering each action with an option, it is covered with options on the index that replicates the behavior of certain actions. With this economy of scale you get better hedge for buyers.

The financial instrument used for the two hedging strategies is the COLCAP stock index of the Colombian stock market. All the available daily data of the index are used to determine the average and the EWMA volatility of the logarithmic returns. The Figure 2 shows the behavior of the COLCAP from January 11, 2008 to January 16, 2018 for a total of 2,685 trading days.

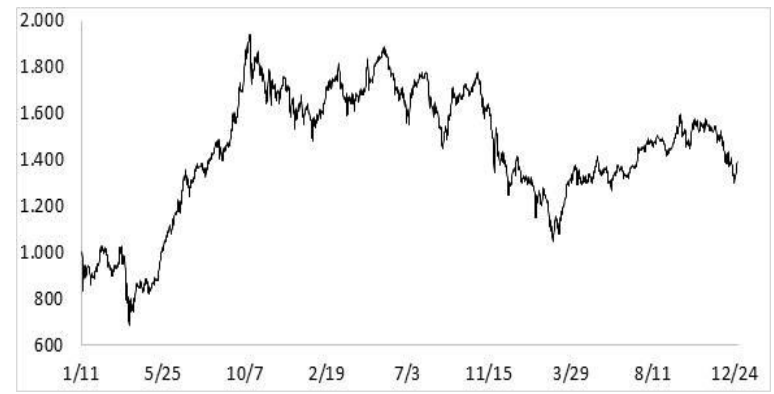

Figure 2. COLCAP stock index behavior

The daily expected return for COLCAP is $0.012 \%$ and the daily volatility is $0.869 \%$. The volatility was calculated by the EWMA (Exponentially Weighted Moving Averages) method, which gives more importance to the most recent observations. The weighting is granted by $\lambda$. According to the RiskMetrics methodology, a value of 0.94 should be used for $\lambda$. The formula for calculating the EWMA volatility is shown in the (3) [17].

$$
\sigma_{t}=(1-\lambda) r_{t-1}+\lambda \sigma_{t-1}
$$

The EWMA volatility of period $\mathrm{t}$ depends on the profitability of the previous period $\left(r_{t-1}\right)$, of the volatility of the previous period $\left(\sigma_{t-1}\right)$ and of the weighting used in lambda.

The Monte Carlo simulation methodology is used to value the premiums of financial options. This methodology is to model the behavior of COLCAP a Geometric Brownian Motion with a neutral risk profitability. According to the modeling, the compensation that the option would have is determined, this compensation is taken to present value using the risk-free rate as the discount rate. Geometrical Brownian motion with Monte Carlo simulation is applied with 50,000 iterations and average compensation at present value is the value of the premium financial option [18, 19]. As shown in (4) shows Geometric Brownian Motion for option premium valuation.

$$
S_{T}=S_{0} * e^{\left(r-\sigma^{2} / 2\right) \Delta t+\sigma \sqrt{\Delta t} \epsilon}
$$

In the (4) $S_{T}$ corresponds to the modeled price of the COLCAP, where $S_{0}$ is the current price of the asset. $\mathrm{r}$ is the risk free rate valid until period T. $\sigma$ is the volatility EWMA, $\Delta$ t represents the period of time that the price will be modeled and $\varepsilon$ is a random variable that has a normal distribution with zero mean and variance equal to one.

The price of an option at maturity is the same as the expected value of the reward terminal, which means that there is no arbitrage and risk neutrality [20]. As shown in (5) shows the price for Call option and the (6) shows the price for Put options.

$$
\begin{aligned}
& \text { Call }=e^{-r T}\left[\max \left(S_{T}-K, 0\right)\right] \\
& \text { Put }=e^{-r T}\left[\max \left(K-S_{T}, 0\right)\right]
\end{aligned}
$$


The two hedging strategies were used for one month, that is, 20 stock days starting on January 16, 2018. The Table 1 shows the data that was used to value the premiums of the options of the two strategies. The strike price of the first strategy is equal to the COLCAP price on January 16, 2018, this strike price was also used for $\mathrm{K}_{1}$ in the second strategy and $\mathrm{K}_{2}$ was $\$ 50$ higher than $\mathrm{K}_{1}$.

After evaluating the options premiums, it becomes a model the price of COLCAP with geometric Brownian motion, but instead of $r$ the average of logarithmic daily returns $(\mu)$ is used. Monte Carlo simulation determines expected prices, percentiles and standard deviations for three scenarios: scenarios without hedge, with call option hedge and hedge with Bull Call Spread.

\begin{tabular}{|c|c|c|}
\hline VARIABLE & VALUE & UNIT \\
\hline $\mathrm{S}_{0}$ & $\$ 1,391.34$ & COP \\
\hline $\mathrm{r}$ & $4.25 \%$ & Annual \\
\hline$\sigma$ & $0.869 \%$ & Daily \\
\hline$\Delta \mathrm{t}$ & 20 & Daily \\
\hline $\mathrm{k}_{1}$ & $\$ 1,391.34$ & $\mathrm{COP}$ \\
\hline $\begin{array}{l}\mathrm{k}_{2} \\
\mathrm{n}\end{array}$ & $\$ 1,441.34$ & $\mathrm{COP}$ \\
\hline
\end{tabular}

\section{RESULTS AND ANALYSIS}

The Table 2 summarizes the results of the modeling and simulation for the scenario without hedge, scenario with hedge with only Call option and scenario with hedge with the Bull Call Spread options portfolio.

Table 2. Results of Modeling and Simulation

\begin{tabular}{lccc}
\hline & WITHOUT HEDGE & CALL & BULL CALL SPREAD \\
\hline Expected price & $\$ 1,395.296$ & $\$ 1,395.785$ & $\$ 1,395.588$ \\
Percentile 5\% & $\$ 1,307.349$ & $\$ 1,331.563$ & $\$ 1,325.100$ \\
Minimum value & $\$ 1,194.969$ & $\$ 1,219.183$ & $\$ 1,212.72$ \\
Maximum value & $\$ 1,650.476$ & $\$ 1,415.554$ & $\$ 1,618.227$ \\
Standard deviation & $\$ 54.49295$ & $\$ 29.78662$ & $\$ 37.94272$ \\
Value paid for premium & Does not apply & $\$ 24.21414$ & $\$ 17.75083$ \\
\hline
\end{tabular}

In the three scenarios, a similar price is expected to be approximately $\$ 1,395$. However, to determine if market risk was mitigated, other factors must be analyzed. Effective hedge means that the possible prices are less dispersed and that the possible harmful scenarios are smaller. In other words, if the distribution of the possible prices does not depart much from the average, it means that it has lower volatility. In the Table 2, the 5\% percentile of the scenario without hedge is the furthest from the average price than the two scenarios with hedge, this means that hedges manage to mitigate market risk. Between the two hedge strategies the most effective is the Call strategy because the 5\% percentile is closer to the average price. The previous behavior is also found when analyzing the minimum value and maximum value. The above indicates that the best hedging strategy is the Call plain vanilla, this is also demonstrated with the standard deviation, between lower standard deviation, lower risk.

On the other hand, the hedging strategy Bull Call Spread is less expensive because you pay less premium, this is because you buy an option on the combination of options and sold another. However, although the Bull Call Spread hedging strategy is less expensive, it is not the one that best mitigates market risk, but it is a good alternative for hedge when there is not enough budget at the time of making the decision to perform hedge.

The Bull Call Spread hedging strategy is not better than the Call because when selling a Call option you are obliged to compensate the buyer in case the price of the asset closes above the $\mathrm{K}_{2}$ price and when the price is above $\mathrm{K}_{1}$ you have the right to receive compensation for having bought a Call. As regards the 50,000 iterations of the Monte Carlo simulation, the average compensation to be received with the Bull Call Spread strategy is $\$ 23.56$ and an average compensation of $\$ 6.18$ will be paid, for a total of average compensation received of $\$ 17.38$. In contrast, with the Call hedging strategy, compensation is only received when the COLCAP price exceeds the $\mathrm{K}_{1}$ price, that is, an average of $\$ 23.56$ would be received. This is why the hedge strategy with Call plain vanilla option is more effective. 


\section{CONCLUSION}

This paper presents two hedging strategies with financial options for buyers of investment portfolios that replicate Colombia's COLCAP stock index. The first strategy is with a Call plain vanilla option and the second with a portfolio of options called Bull Call Spread. To determine the best hedging strategy, Monte Carlo simulation is used to the Geometric Brownian Motion applied to the price of the COLCAP index.

The market risk that is mitigated by the hedging strategies is the risk of rising stock prices in the Colombian market. The first strategy is to buy a Call option with a strike price equal to the COLCAP index, that is, ATM option. The second strategy is the purchase of the previous option combined with the sale of an ITM Call option with a strike price greater than the COLCAP index of \$50. In the first strategy, the option premium must be paid, while in the second strategy this option is paid, but the payment of the second option premium is received.

The two hedging strategies proposed mitigate the market risk for buyers who, within a month, will obtain an investment portfolio that replicates the COLCAP index. However, the best strategy is the first, although the second strategy is lower cost. This is due to the fact that greater value is obtained in compensation with the first strategy than with the second. In contrast, the second strategy is ideal when the investor does not have enough budget at the time of making the decision to cover the purchase of the investment portfolio.

\section{REFERENCES}

[1] C. W. Smith and R. M. Stulz, "The Determinants of Firms Hedging Policies," J. Financ. Quant. Anal., vol. 20, no. 4, pp. 391-405, 1985.

[2] Y. Ayturk, A. Osman, and S. Yanik, "Corporate derivatives use and firm value: Evidence from Turkey," Borsa Istanbul Rev., vol. 16, no. 2, pp. 108-120, 2016.

[3] M. M. Arnold, A. W. Rathgeber, and S. Stöckl, "Determinants of corporate hedging: A (statistical) meta-analysis," Q. Rev. Econ. Financ., vol. 54, no. 4, pp. 443-458, 2014.

[4] D. M. Sprčić, M. Tekavcic, and Z. Sevic, "A review of the rationales for corporate risk management: fashion or the need?,” Int. J. Econ. Sci. Appl. Res., vol. 1, pp. 71-99, 2008.

[5] N. L. Joseph, "The choice of hedging techniques and the characteristics of UK industrial firms," J. Multinatl. Financ. Manag., vol. 10, no. 2, pp. 161-184, 2000.

[6] A. Judge, "Why and how UK firms hedge," Eur. Financ. Manag., vol. 12, no. 3, pp. 407-441, 2006.

[7] C. S. Tai, "Asymmetric currency exposure and currency risk pricing," Int. Rev. Financ. Anal., vol. 17, no. 4, pp. 647-663, 2008.

[8] K. M. E. Dominguez and L. L. Tesar, "Exchange rate exposure. Journal of International Economics," J. Int. Econ., vol. 68 , no. 1, pp. $188-218,2006$.

[9] L. Jiménez, N. Acevedo, and N. Castaño, "Cobertura cambiaria por medio de instrumentos derivados para empresa exportadora de flores en Colombia," En-Contexto, vol. 4, no. 5, pp. 119-138, 2016.

[10] Y. Chen, Z. Wang, and Z. Zhang, "Mark to market value at risk," J. Econom., vol. 208, no. 1, pp. 299-321, 2019.

[11] Z. Cai, G. Chen, L. Xing, J. Yang, and X. Tan, "Evaluating Hedge Fund Downside Risk using a Multi-objective Neural Network," J. Vis. Commun. Image Represent., 2018.

[12] L. Franco and J. Murillo, "Loss distribution approach (LDA): metodología actuarial aplicada al riesgo operacional," Ing. Univ. Medellín, vol. 7, no. 13, pp. 143-156, 2008.

[13] F. Venegas-Martínez, G. Agudelo Torres, L. Franco Arbeláez, and L. Franco Ceballos, "Precio del dólar estadounidense en el mundo Procesos de Itô económicamente ponderados en un análisis espacial," Econ. y Soc., vol. 34, no. 20, pp. 83-105, 2016.

[14] M. Rusnáková, V. Šoltés, and Z. Katalin Szabo, "Short Combo Strategy Using Barrier Options and its Application in Hedging," Procedia Econ. Financ., vol. 32, pp. 166-179, 2015.

[15] C. Lin, Y. Liu, and A. Chen, "Hedging an option portfolio with minimum transaction lots: A fuzzy goal programming problem," Appl. Soft Comput. J., vol. 47, pp. 295-303, 2016.

[16] E. Gaarder and N. Taleb, "Option traders use (very) sophisticated heuristics, never the Black-Scholes-Merton formula," J. Econ. Behav. Organ., vol. 77, no. 2, pp. 97-106, 2011.

[17] S. MEDINA Hurtado, J. RESTREPO, L. URREGO Agudelo, and F. HÉLIODORE, "Comparison of Pricing Models of Options over Futures Contracts for the Colombian Electricity Market," Espacios, vol. 36, no. N ${ }^{\mathrm{O}} 10$, p. $16,2015$.

[18] D. Allen, M. McAleerc, and M. Scharth, "Monte Carlo option pricing with asymmetric realized volatility dynamics," Math. Comput. Simul., vol. 81, no. 7, p. Pages 1247-1256, 2011.

[19] C. N. Angstmann, B. I. Henry, and A. V. McGann, "Time-fractional geometric Brownian motion from continuous time random walks," Phys. A Stat. Mech. its Appl., vol. 526, p. 121002, 2019.

[20] L. Haar and L. Haar, "A financial option perspective on energy security and strategic storage," Energy Strateg. Rev., vol. 25, no. August, pp. 65-74, 2019. 